\title{
A New Supramolecular Assembly Obtained by Reaction Between Thiosaccharin and Hexamethylenediamine
}

Enrique J. Baran ${ }^{\mathrm{a}}$, Oscar E. Piro ${ }^{\mathrm{b}}$, and Juan Zinczuk ${ }^{\mathrm{c}}$

${ }^{a}$ Centro de Química Inorgánica (CEQUINOR, CONICET/UNLP), Facultad de Ciencias Exactas,

Universidad Nacional de La Plata, C. Correo 962, 1900 La Plata, Argentina

${ }^{\mathrm{b}}$ Departamento de Física and Instituto IFLP (CONICET), Facultad de Ciencias Exactas,

Universidad Nacional de La Plata, 1900 La Plata, Argentina

${ }^{c}$ Instituto de Química Orgánica de Síntesis (IQUIOS/CONICET, UNR), Facultad de Ciencias

Bioquímicas y Farmacéuticas, Universidad Nacional de Rosario, 2000 Rosario, Argentina

Reprint requests to Dr. E. J. Baran. E-mail: baran@quimica.unlp.edu.ar

Z. Naturforsch. 2007, 62b, 1530 - 1534; received June 1, 2007

The crystal structure of hexamethylenediammonium bis(thiosaccharinate) dihydrate,

$\left[\mathrm{H}_{3} \mathrm{~N}-\left(\mathrm{CH}_{2}\right)_{6}-\mathrm{NH}_{3}\right]$ (tsac) $)_{2} \cdot 2 \mathrm{H}_{2} \mathrm{O}\left(\mathrm{tsac}=\mathrm{C}_{7} \mathrm{H}_{4} \mathrm{NO}_{2} \mathrm{~S}_{2}\right.$, the anion of thiosaccharin), was determined by single-crystal $\mathrm{X}$-ray diffraction. It crystallizes in the monoclinic space group $P 2{ }_{1} / a$ with $Z=4$. The thiosaccharinate moiety is planar and shows small but significant modifications in the bonding of the thioamide functional group as compared with the protonated neutral molecule. The ionic crystal is further stabilized by an extensive H-bonding network, which links the anions and cations into an infinite three-dimensional supramolecular assembly. The FTIR spectrum of the compound is briefly discussed in comparison with those of the neutral constituent molecules.

Key words: Hexamethylenediammonium Bis(thiosaccharinate) Dihydrate, Crystallographic Data, Supramolecular Adduct, IR Spectra

\section{Introduction}

In the last years we have synthesized and characterized a number of metallic complexes of thiosaccharin (for a recent review $c f$. [1]), and have now initiated a search to verify the possible formation of supramolecular adducts between thiosaccharin and some simple organic amines. In this paper, we present the first compound of this type, hexamethylenediammonium bis (thiosaccharinate) dihydrate, generated by interaction of thiosaccharin with hexamethylenediamine (1,6-hexanediamine).

\section{Results and Discussion}

\section{Crystal and molecular structure}

An ORTEP [2] drawing of the structure is presented in Fig. 1. Selected bond lengths and angles are shown in Table 1. As expected, the thiosaccharinate $\mathrm{C}_{7} \mathrm{H}_{4} \mathrm{NO}_{2} \mathrm{~S}_{2}{ }^{-}$molecular skeletons are nearly planar (r.m.s. distance of atoms from least-squares planes less than $0.0194 \AA$ ). A comparison with the structure of the neutral thiosaccharin (tsac) molecule [3] shows that the major bonding changes in the charged moi-

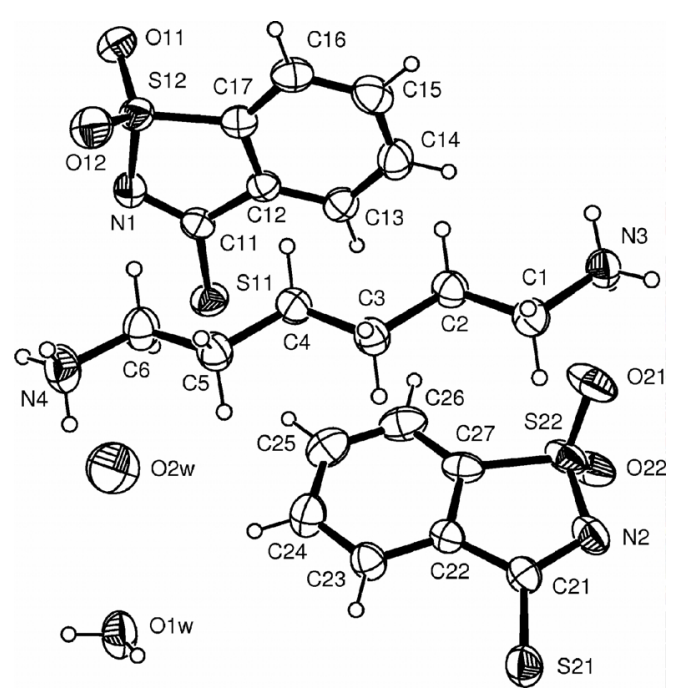

Fig. 1. ORTEP plot of the molecular structure of $\left[\mathrm{H}_{3} \mathrm{~N}-\left(\mathrm{CH}_{2}\right)_{6}-\mathrm{NH}_{3}\right](\mathrm{tsac})_{2} \cdot 2 \mathrm{H}_{2} \mathrm{O}$ showing the labeling of the non-H atoms and their displacement ellipsoids at the $30 \%$ probability level.

ety occur at the thioamide functional group, as also predicted by a previous quantum chemical study [4]. In fact, upon deprotonation, the excess nitrogen elec- 
Table 1. Selected interatomic bond lengths $(\AA)$ and angles $\left(^{\circ}\right)$ in $\left[\mathrm{NH}_{3}-\left(\mathrm{CH}_{2}\right)_{6}-\mathrm{NH}_{3}\right](\mathrm{tsac})_{2} \cdot 2 \mathrm{H}_{2} \mathrm{O}$.

\begin{tabular}{lrll}
\hline $\mathrm{S}(11)-\mathrm{C}(11)$ & $1.681(4)$ & $\mathrm{N}(1)-\mathrm{C}(11)$ & $1.326(5)$ \\
$\mathrm{S}(12)-\mathrm{O}(11)$ & $1.430(3)$ & $\mathrm{N}(3)-\mathrm{C}(1)$ & $1.488(5)$ \\
$\mathrm{S}(12)-\mathrm{O}(12)$ & $1.435(3)$ & $\mathrm{N}(4)-\mathrm{C}(6)$ & $1.478(6)$ \\
$\mathrm{S}(12)-\mathrm{N}(1)$ & $1.632(4)$ & $\mathrm{C}(1)-\mathrm{C}(2)$ & $1.500(5)$ \\
$\mathrm{S}(12)-\mathrm{C}(17)$ & $1.752(4)$ & $\mathrm{C}(3)-\mathrm{C}(4)$ & $1.505(5)$ \\
$\mathrm{S}(21)-\mathrm{C}(21)$ & $1.676(4)$ & $\mathrm{C}(5)-\mathrm{C}(6)$ & $1.506(5)$ \\
$\mathrm{S}(22)-\mathrm{C}(27)$ & $1.742(5)$ & $\mathrm{C}(11)-\mathrm{C}(12)$ & $1.479(5)$ \\
$\mathrm{C}(12)-\mathrm{C}(17)$ & $1.394(5)$ & $\mathrm{C}(22)-\mathrm{C}(27)$ & $1.394(5)$ \\
$\mathrm{O}(11)-\mathrm{S}(12)-\mathrm{O}(12)$ & $115.6(2)$ & $\mathrm{N}(4)-\mathrm{C}(6)-\mathrm{C}(5)$ & $111.6(4)$ \\
$\mathrm{O}(11)-\mathrm{S}(12)-\mathrm{N}(1)$ & $110.0(2)$ & $\mathrm{N}(1)-\mathrm{C}(11)-\mathrm{C}(12)$ & $114.0(4)$ \\
$\mathrm{O}(12)-\mathrm{S}(12)-\mathrm{N}(1)$ & $110.1(2)$ & $\mathrm{N}(1)-\mathrm{C}(11)-\mathrm{S}(11)$ & $123.8(3)$ \\
$\mathrm{O}(11)-\mathrm{S}(12)-\mathrm{C}(17)$ & $111.9(2)$ & $\mathrm{C}(12)-\mathrm{C}(11)-\mathrm{S}(11)$ & $122.1(3)$ \\
$\mathrm{O}(12)-\mathrm{S}(12)-\mathrm{C}(17)$ & $111.0(2)$ & $\mathrm{N}(3)-\mathrm{C}(1)-\mathrm{C}(2)$ & $110.3(3)$ \\
$\mathrm{N}(1)-\mathrm{S}(12)-\mathrm{C}(17)$ & $96.6(2)$ & $\mathrm{C}(1)-\mathrm{C}(2)-\mathrm{C}(3)$ & $113.2(3)$ \\
$\mathrm{C}(11)-\mathrm{N}(1)-\mathrm{S}(12)$ & $111.4(3)$ & $\mathrm{C}(4)-\mathrm{C}(3)-\mathrm{C}(2)$ & $112.7(3)$ \\
\hline
\end{tabular}

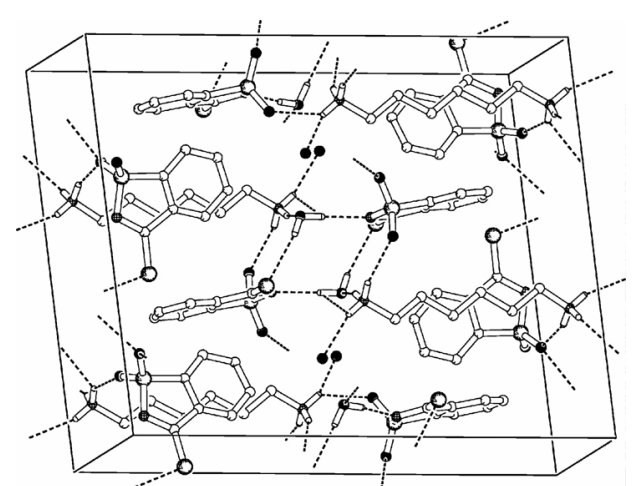

Fig. 2. Crystal packing of $\left[\mathrm{H}_{3} \mathrm{~N}-\left(\mathrm{CH}_{2}\right)_{6}-\mathrm{NH}_{3}\right](\text { tsac })_{2}$. $2 \mathrm{H}_{2} \mathrm{O}$ as viewed down the $b$ axis (PLATON [9]). The crystal $a$ axis is along the vertical. For clarity, only hydrogen atoms involved in $\mathrm{H}$-bonding are shown. $\mathrm{H}$ bonds are indicated by dashed lines. Sulfur atoms are denoted by larger shaded circles, while oxygen and nitrogen atoms are indicated by the smaller black discs.

tron mainly contributes to a delocalized $\mathrm{N}-\mathrm{C}-\mathrm{S}$ bonding. This is shown by the shortening observed in both $\mathrm{N}-\mathrm{C}$ bonds (from $1.384 \AA$ in neutral tsac to $1.326(5)$ and $1.327(5) \AA$ in the two anions present in the investigated adduct) and the lengthening of the $\mathrm{C}-\mathrm{S}$ bonds (from 1.622 $\AA$ in tsac to 1.681(4) and 1.676(4) $\AA$ in the present compound). In contrast, no significant changes are observed for the $\mathrm{C}(12)-\mathrm{C}(17)$ and $\mathrm{C}(22)-\mathrm{C}(27)$ and the sulfonyl S-O bond lengths comparing the neutral and charged molecules. On the other hand, the bond lengths and angles in the title compound agree well with those reported for the sodium, potassium, ammonium and bis(triphenylphosphinium) thiosaccharinate salts [5-8].

The crystal is further stabilized by the extensive 3-D net of hydrogen bonds shown in the PLA-
TON [9] plot (Fig. 2). The H-bonding structure involves both hexamethylenediammonium $\mathrm{NH}_{3}$ groups as donors, and as acceptors the exocyclic sulfur atom of one thiosaccharinate $[d(\mathrm{~N} 3 \cdots \mathrm{S} 21)=3.210 \AA$ and $\angle(\mathrm{N} 3-\mathrm{H} \cdots \mathrm{S} 21)=161.4^{\circ}$, the sulfonyl oxygen atoms of neighboring thiosaccharinate ions [the strongest with $d(\mathrm{~N} 3 \cdots \mathrm{O} 22)=2.937 \AA$ and $\angle(\mathrm{N} 3 \cdots \mathrm{O} 22)=$ $159.0^{\circ}$ ] and the water oxygen atoms [the strongest with $d(\mathrm{~N} 4 \cdots \mathrm{O} 1 \mathrm{w})=2.813 \AA$ and $\angle(\mathrm{N} 4-\mathrm{H} \cdots \mathrm{O} 1 \mathrm{w})=$ $161.2^{\circ}$ ]. This latter water molecule, in turn, acts as donor in a pair of $\mathrm{H}$ bonds, one with the other exocyclic $\mathrm{S}$ atom $[d(\mathrm{O} 1 \mathrm{w} \cdots \mathrm{S} 11)=3.230 \AA$ and $\angle(\mathrm{O} 1 \mathrm{w}-$ $\left.\mathrm{H} \cdots \mathrm{S} 11)=158.1^{\circ}\right]$, the other with the imino $\mathrm{N}$ atom $(\mathrm{N} 1)$ of one thiosaccharinate anion $[d(\mathrm{O} 1 \mathrm{w} \cdots \mathrm{N} 1)=$ $2.835 \AA$ and $\left.\angle(\mathrm{O} 1 \mathrm{w}-\mathrm{H} \cdots \mathrm{N} 1)=168.4^{\circ}\right]$. Further details of the crystal H-bonding are presented in Table 2.

In the case of the recently described adduct of saccharin, $\left[\mathrm{H}_{3} \mathrm{~N}-\left(\mathrm{CH}_{2}\right)_{6}-\mathrm{NH}_{3}\right](\mathrm{sac})_{2}$ (space group $P 2_{1} / c$, $Z=4$ ), the extended hydrogen bonding system also involves all six $\mathrm{NH}_{3}$ hydrogen atoms as donors as well as the six $\mathrm{O}$ atoms belonging to the two saccharinate anions as acceptors [10].

\section{Infrared spectra}

The assignment of some of the most characteristic IR bands of the investigated compound is shown in Table 3. For comparative purposes we have also measured the spectrum of the free amine, and known data for the thiosaccharin molecule are also included $[11,12]$. Standard references $[13,14]$ were used in the analysis and assignment of the spectra. Some aspects of the proposed assignments are commented as follows:

- In the case of the free amine a relative broad band is observed in the high-frequency range and only one of the two expected $\mathrm{N}-\mathrm{H}$ stretching bands of the $\mathrm{NH}_{2}$ groups could be observed. The same behavior was observed for the $v\left(\mathrm{NH}_{3}{ }^{+}\right)$vibrations in the case of the salt.

- The characteristic deformational bands of the primary amine groups are absent in the salt, instead of which those of the ammonium groups $\left(\mathrm{R}-\mathrm{NH}_{3}{ }^{+}\right)$are observed.

- The stretching vibrations of the water molecules generate a very broad and ill-defined band, centered at about $3490 \mathrm{~cm}^{-1}$, pointing to a participation in hydrogen bridges of medium length [15]. The respective bending motion causes only a very weak shoulder at 


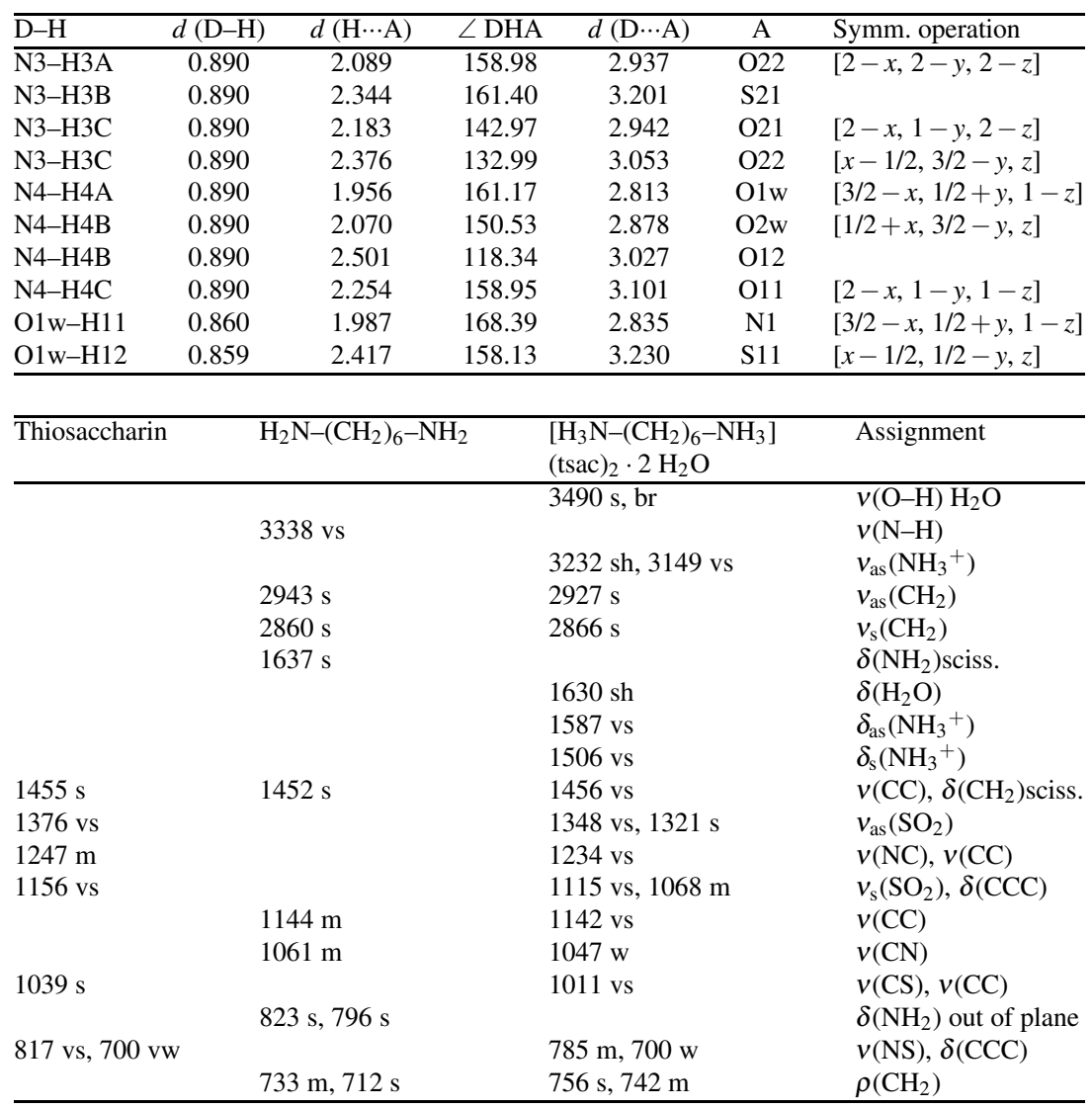

Table 2. Hydrogen bonds of $\left[\mathrm{H}_{3} \mathrm{~N}-\left(\mathrm{CH}_{2}\right)_{6}-\mathrm{NH}_{3}\right]$ (tsac) $)_{2}$. $2 \mathrm{H}_{2} \mathrm{O}$ (in A, angles in degrees).

Table 3. Assignment of some of the most characteristic IR bands of $\left[\mathrm{H}_{3} \mathrm{~N}-\left(\mathrm{CH}_{2}\right)_{6}-\mathrm{NH}_{3}\right](\text { tsac })_{2}$. $2 \mathrm{H}_{2} \mathrm{O}, \mathrm{H}_{2} \mathrm{~N}-\left(\mathrm{CH}_{2}\right)_{6}-\mathrm{NH}_{2}$, and thiosaccharin ${ }^{\mathrm{a}}$.

a vs: very strong; s: strong; m: medium; w: weak; sh: shoulder; br: broad.
$1630 \mathrm{~cm}^{-1}$, at the higher energy side of the very strong $\delta_{\text {as }}\left(\mathrm{NH}_{3}{ }^{+}\right)$band located at $1587 \mathrm{~cm}^{-1}$.

- Some of the characteristic $v(\mathrm{CC}), \delta(\mathrm{CCC})$ and $\mathrm{CH}_{2}$ bands could also be unambiguously identified. Interestingly, the $\mathrm{CH}_{2}$-rocking mode shows the typical splitting [19] in both, the free amine and the adduct.

- Three of the most typical thiosaccharinate bands, i. e. the two $\mathrm{SO}_{2}$ stretchings, and the $v(\mathrm{CS})$ mode are clearly displaced to lower energies in $\left[\mathrm{H}_{3} \mathrm{~N}-\left(\mathrm{CH}_{2}\right)_{6}-\right.$ $\left.\mathrm{NH}_{3}\right]$ (tsac) $)_{2} \cdot 2 \mathrm{H}_{2} \mathrm{O}$ in comparison to their position in free thiosaccharin, surely as a consequence of its ionization [4] and involvement in hydrogen bonding, as commented above. Besides, both the $v_{\mathrm{as}}\left(\mathrm{SO}_{2}\right)$ and the $v_{\mathrm{S}}\left(\mathrm{SO}_{2}\right)$ vibrations appear as a singly split absorption band. On the other hand, the $v(\mathrm{NC})$ and $v(\mathrm{NS})$ bands of thiosaccharin are displaced to lower frequencies in the salt.

- The $v(\mathrm{CN})$ vibration of the amine is also affected by the salt formation as are also some of the characteristic vibrations of the $\mathrm{CH}_{2}$ groups.
To conclude, this brief spectroscopic analysis is clearly compatible and consistent with the structural characteristics of the compound and reflects nicely its peculiarities.

\section{Experimental Section}

Synthesis of the adduct

Thiosaccharin (1,2-benzisothiazol-3(2H)-thione-1,1-dioxide) was obtained by heating of a mixture of $0.1 \mathrm{~mol}$ of saccharin (Aldrich, $99 \%$ ) and $0.11 \mathrm{~mol}$ of $\mathrm{P}_{2} \mathrm{~S}_{5}$ (Merck) under an $\mathrm{N}_{2}$ atmosphere, according to the procedure described by Meadow and Cavagnol [16]. The reaction product was extracted with benzene and the crude orange-yellow product was recrystallized from benzene. Its purity was confirmed by the melting point $\left(181-182{ }^{\circ} \mathrm{C}\right)$ and by IR and Raman spectra [11].

The adduct was obtained by addition of $1.0 \mathrm{mmol}$ of hexamethylenediamine to an aqueous solution $(15 \mathrm{~mL})$ containing $2.0 \mathrm{mmol}$ of thiosaccharin. The mixture was heated with stirring for $10 \mathrm{~min}$ at $80{ }^{\circ} \mathrm{C}$. The resulting solution was filtered, and the filtrate was slowly evaporated 
Table 4. Crystal data and details of the structure refinement of $\left[\mathrm{H}_{3} \mathrm{~N}-\left(\mathrm{CH}_{2}\right)_{6}-\mathrm{NH}_{3}\right](\text { tsac })_{2} \cdot 2 \mathrm{H}_{2} \mathrm{O}$.

\begin{tabular}{ll}
\hline Formula & $\mathrm{C}_{20} \mathrm{H}_{30} \mathrm{~N}_{4} \mathrm{O}_{6} \mathrm{~S}_{4}$ \\
Formula weight & 550.72 \\
Crystal system & monoclinic \\
Space group & $P 2{ }_{1} / a(\mathrm{Nr} .14)$ \\
$a, \AA$ & $16.385(2)$ \\
$b, \AA$ & $7.927(1)$ \\
$c, \AA$ & $20.280(1)$ \\
$\beta$, deg & $93.95(1)$ \\
$V\left(\AA^{3}\right)$ & $2627.8(5)$ \\
$D_{\mathrm{c}}\left(\mathrm{g} \cdot \mathrm{cm}^{-3}\right)$ & 1.392 \\
$Z$ & 4 \\
$F(000)$ & 1160 \\
$\theta$ Range for data collection & $2.18-67.99$ \\
Index ranges $h k l$ & $-19 \leq h \leq 0 ;$ \\
& $-1 \leq k \leq 9 ;$ \\
Reflections collected & $-24 \leq l \leq 24$ \\
Independent reflections & 5473 \\
$R($ int $)$ & 4515 \\
Observed reflections $[I \geq 2 \sigma(I)]$ & 0.050 \\
Data/restraints/parameters & 3371 \\
Goodness-of-fit on $F^{2}$ & $4515 / 3 / 323$ \\
$R 1 / w R 2[I \geq 2 \sigma(I)]$ & 1.036 \\
$R 1 / w R 2($ all data) & $0.0671 / 0.1807$ \\
Largest diff. peak and hole, e $\AA^{-3}$ & $0.086 / 0.211$ \\
\hline & $0.80 /-0.39$ \\
\hline
\end{tabular}

at r.t. The obtained yellow microcrystalline product was recrystallized twice from methanol, and after the slow evaporation of the solvent a few, very small crystals adequate for crystallographic studies could be selected under the microscope.

\section{Crystal structure determination}

Measurements were performed at 296(2) K, with an Enraf-Nonius CAD-4 diffractometer employing graphite monochromated $\mathrm{Cu} K_{\alpha}$ radiation $(\lambda=1.54184 \AA)$. A colorless prismatic crystal of dimensions $0.31 \times 0.17 \times 0.08 \mathrm{~mm}$ was used. Crystal data, collection procedures and refinement results are summarized in Table 4. The thiosacchari- nate and hexamethylenediammonium hydrogen atoms were located in calculated positions and refined with the riding model. The $\mathrm{H}$ positions of the $\mathrm{H}_{3} \mathrm{~N}-\left(\mathrm{CH}_{2}\right)_{2}-\mathrm{NH}_{3}$ terminal ammonium groups were optimized by treating them as rigid groups which were allowed to rotate during the refinement around the corresponding $\mathrm{N}-\mathrm{C}$ bonds. As a result, both $\mathrm{NH}_{3}$ groups converged to staggered conformations. The $\mathrm{H}$ atoms of one water molecule were located in a difference Fourier map and refined isotropically with $\mathrm{O}-\mathrm{H}$ and $\mathrm{H} \cdots \mathrm{H}$ distances restrained to target values of $0.86(1)$ and 1.36(1) $\AA$, respectively. The other water molecule showed positional disorder and therefore its $\mathrm{H}$ atoms could not be determined reliably to be included in the final molecular model.

Intensity data were corrected for Lorentz and polarization effects as well as for absorption (PLATON [9]). The unit cell dimensions were obtained by least-squares refinement of the angular settings for 23 reflections in the range $16.54<\theta<41.21^{\circ}$. Programs used were CAD4 [17], XCAD-4 [18], and SHELXS-97 [19] for data reduction and correction and structure solution and SHELXL-97 [20] for structure refinement.

CCDC 653328 contains the supplementary crystallographic data for this paper. These data can be obtained free of charge from The Cambridge Crystallographic Data Centre via www.ccdc.cam.ac.uk/data_request/cif.

\section{Spectroscopic measurements}

The infrared spectra of the compound as well as that of free hexamethylenediamine were recorded in the spectral range between 4000 and $400 \mathrm{~cm}^{-1}$ on a FTIR Bruker IFS 66 spectrophotometer, using the $\mathrm{KBr}$ pellet technique.

\section{Acknowledgements}

This work has been supported by the Consejo Nacional de Investigaciones Científicas y Técnicas de la República Argentina (CONICET) and the Universidad Nacional de La Plata (UNLP). The authors are members of the Research Career from CONICET.
[1] E. J. Baran, V. T. Yilmaz, Coord. Chem. Rev. 2006, 250, $1980-1999$.

[2] C. K. Johnson, ORTEP-II. A Fortran Thermal-Ellipsoid Plot Program, Report ORNL-5318, Oak Ridge National Laboratory, Tennessee, USA, 1976.

[3] O. Grupce, M. Penavic, G. Jovanovski, J. Chem. Crystallogr. 1984, 24, 581-586.

[4] M. M. Branda, N. J. Castellani, S. H. Tarulli, O. V. Quinzani, E. J. Baran, R. H. Contreras, Internat. J. Quant. Chem. 2002, 89, 525-534.

[5] M. Penavic, G. Jovanovski, O. Grupce, Acta Crystal$\log r$ 1990, C46, $2341-2344$.
[6] M. Penavic, O. Grupce, G. Jovanovski, Acta Crystallogr. 1991, C47, 1821 - 1823

[7] E. J. Baran, O.E. Piro, J. Zinczuk, Z. Anorg. Allg. Chem. 2006, 632, 437-440.

[8] M. Dennehey, O. V. Quinzani, S.D. Mandolesi, J. Guida, G. A. Echeverría, O. E. Piro, Monatsh. Chem., in press.

[9] A. L. Spek, Platon, A Multipurpose Crystallographic Tool, University of Utrecht, Utrecht (The Netherlands) 1998.

[10] Z. L. Wang, L. H. Wei, M. X. Li, J. Y. Niu, Acta Crystallogr. 2006, E62, o1314-o1316. 
[11] E. J. Baran, J. Zinczuk, J. Raman Spectr. 2006, 37, $948-950$.

[12] S. H. Tarulli, O. V. Quinzani, O.E. Piro, E. J. Baran, E.E. Castellano, Monatsh. Chem. 2001, 132, 779787.

[13] D. Lin-Vien, N. B. Colthup, W. G. Fateley, J. G. Grasselli, Infrared and Raman Characteristic Frequencies of Organic Molecules, Academic Press, San Diego, 1991.

[14] B. Smith, Infrared Spectral Interpretation, CRC Press, Boca Raton, 1999.

[15] H. Siebert, Anwendungen der Schwingungsspektroskopie in der Anorganischen Chemie, Springer, Berlin, 1966.
[16] J. R. Meadow, J. C. Cavagnol, J. Org. Chem. 1951, 16, $1582-1587$.

[17] CAD4 Express Software. Enraf-Nonius, Delft (The Netherlands) 1994.

[18] K. Harms, S. Wocadlo, XCAD-4. Program for Processing CAD-4 Diffractometer Data. University of Marburg, Marburg (Germany) 1995.

[19] G. M. Sheldrick, SHELXS-97, Program for the Solution of Crystal Structures, University of Göttingen, Göttingen (Germany) 1997.

[20] G. M. Sheldrick, SHELXL-97, Program for the Refinement of Crystal Structures, University of Göttingen, Göttingen (Germany) 1997. 